\title{
Breast Cancer in the Presence of Failed Saline Breast Implants
}

\author{
Sherif Monib ${ }^{1}$, Simon Thomson ${ }^{1}$ \\ 1. Breast Surgery, West Hertfordshire Hospitals NHS Trust, St. Albans, GBR
}

Corresponding author: Sherif Monib, sherif.monib@nhs.net

\begin{abstract}
Breast augmentation has been gaining popularity over the last two decades to correct congenital breast asymmetry or increase breast size and projection. Augmentation options started with saline implants, then silicone implants, and, recently, autologous fat transfer.
\end{abstract}

Unfortunately, breast implants are not without complications, some of which are common, like capsular contracture, implant failure and infection. Others are quite rare, such as Breast Implant-Associated Anaplastic Large Cell Lymphoma (BIA-ALCL). Most of these complications will eventually require explantation in most cases, as the patients' and implants' age and risk of complications increase.

We present a 79-year-old patient who presented to our breast unit with a left breast lump with 50-year-old saline implants. A triple assessment revealed incidental right breast cancer treated with radiofrequency identification (RFID) tag-guided wide local excision, sentinel lymph node biopsy and bilateral explantation.

Categories: General Surgery

Keywords: breast cancer, breast implant, saline implant, failed implant

\section{Introduction}

Breast augmentation started gaining popularity in the sixties until it became the second-most popular form of cosmetic surgery worldwide. With recent advances in medical sciences and appreciation of the importance of considering patients' psychological and physical needs, different breast options for augmentation evolved to better achieve patients' satisfaction. Various types of breast implants have facilitated tailoring breast augmentation and reconstruction to the patients' needs, to achieve the desired shape, size and symmetry.

The lifetime incidence of female breast cancer is approximately $12.3 \%$. About $48 \%$ of cancers are seen in patients over 65 , and about $30 \%$ of those cases are seen in the population over 70 [1]. The incidence of breast cancer in women with implants is on the rise due to the marked increase in breast augmentation surgeries using breast implants in recent years. This group of patients' clinical management is challenging, as aesthetic results following breast-conserving surgery are likely to be compromised due to different cancer

Review began 03/28/2021 Review ended 03/30/2021 Published 03/31/2021

\section{() Copyright 2021}

Monib et al. This is an open access article distributed under the terms of the Creative Commons Attribution License CC-BY 4.0., which permits unrestricted use, distribution, and reproduction in any medium, provided the original author and source are credited. treatment modalities or implant-related complications [2].

As patients and implants age, the incidence of breast cancer and implant-related complications increases [3], so clinicians will be faced with a group of patients, who are relatively old, diagnosed with breast cancer in the presence of failing or failed implants. Unfortunately, this group of patients is not well-represented in the literature. There is no consensus on surgical management. Often, their treatment is based on the clinician's experience rather than solid guidelines.

We are presenting a case of breast cancer who had one of the very early saline breast implants for augmentation.

\section{Case Presentation}

We present a case of a 79-year-old independent female who was referred to our breast unit with a left breast lump. Her past medical history included bilateral implant-based breast augmentation in 1970, hypertension, myocardial infarction in 1979 and 1982, coronary stents, atrioventricular (AV) node ablation, and atrial fibrillation (AF). There was no relevant family history, and the general examination was unremarkable. Breast examination revealed bilateral hard $50 \mathrm{~mm}$ masses in each breast's centre, denoting grade IV capsular contracture (as per Baker scale [4]) and likely failed breast implants, with no other palpable suspicious lumps or axillary or supraclavicular lymphadenopathy.

Bilateral mammogram and ultrasound scan showed an impalpable, right breast, $10 \mathrm{~mm}$, suspicious mass, which was cored and clipped under ultrasound scan guidance. They also showed bilateral failed collapsed breast implants (Figures 1-2). 


\section{Cureus}

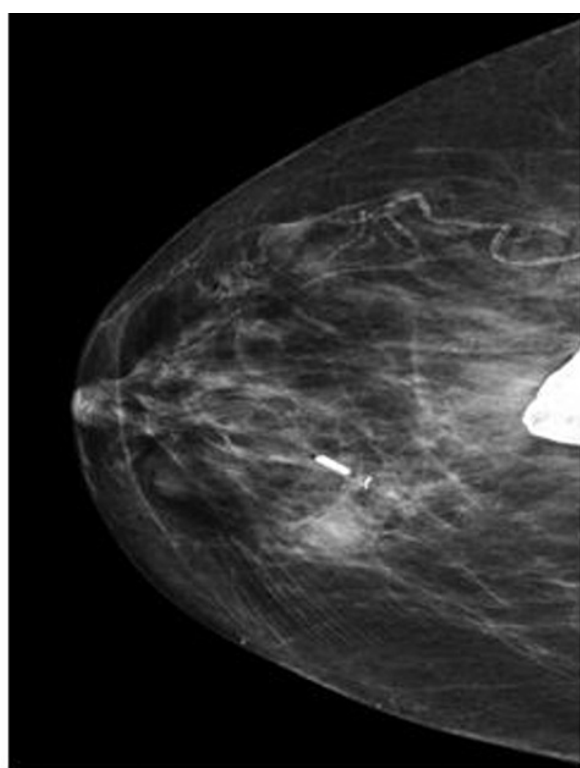

Right breast cranio-caudalview showing the index lesion marked by a Titanium clip and a RFIDTag with the collapsed implant also seen

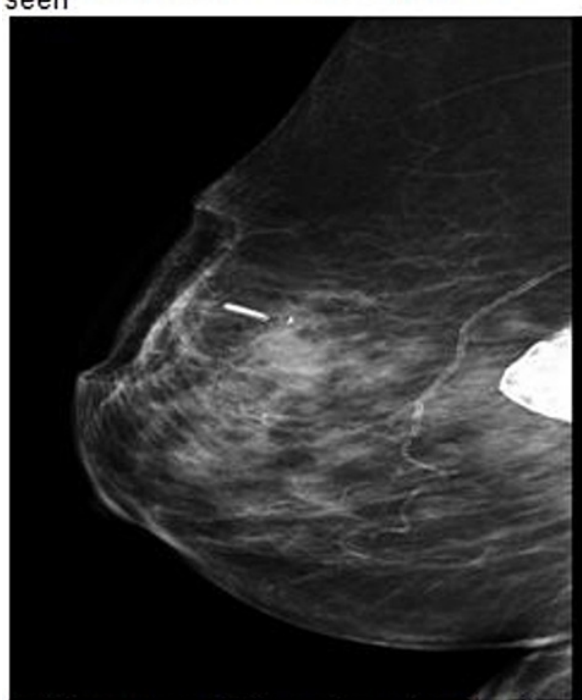

Right breast medio lateral view showing the index lesion marked by a Titanium clip and a RFIDTag with the collapsed implant also seen

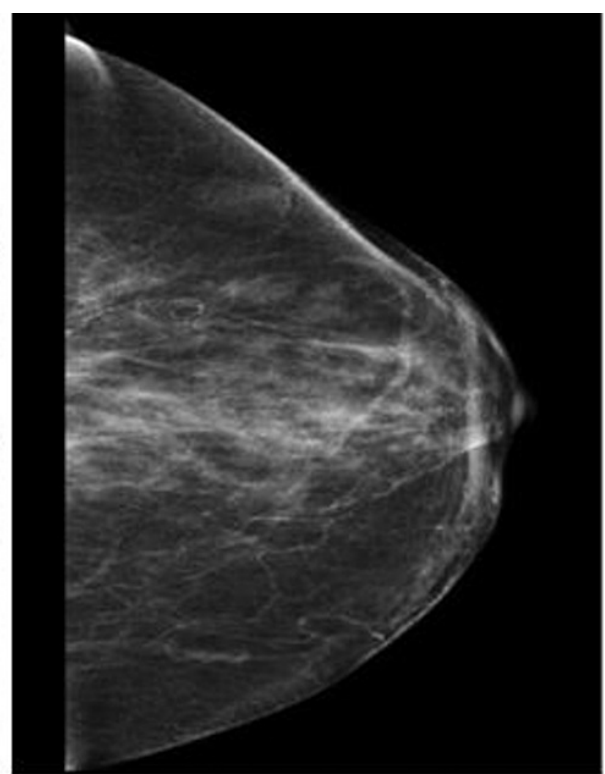

Left breast cranio-caudal view showing no breastlesions, but collapsedimplant not seen in this view

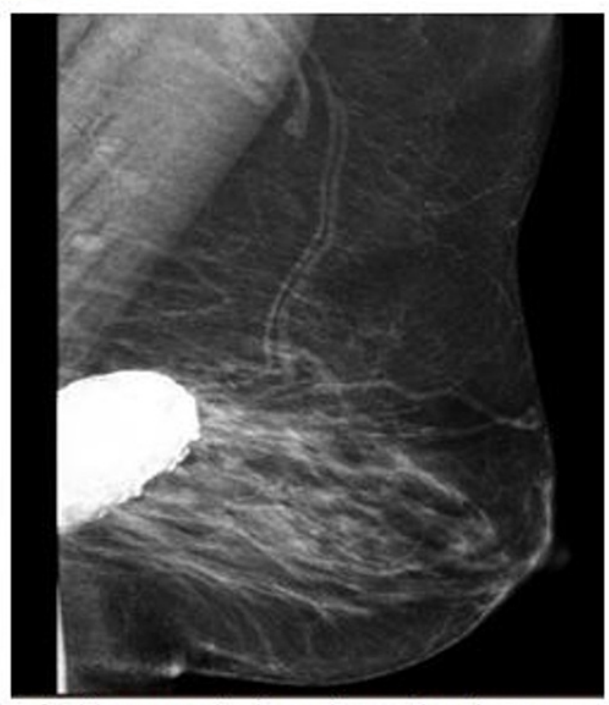

Left oblique medio-lateral view showing no breast lesions, but collapsedimplant seen in this view

FIGURE 1: Preoperative cranio-caudal and medio-lateral mammograms showing the right breast cancer area, as well as bilateral calcified failed implants 


\section{Cureus}

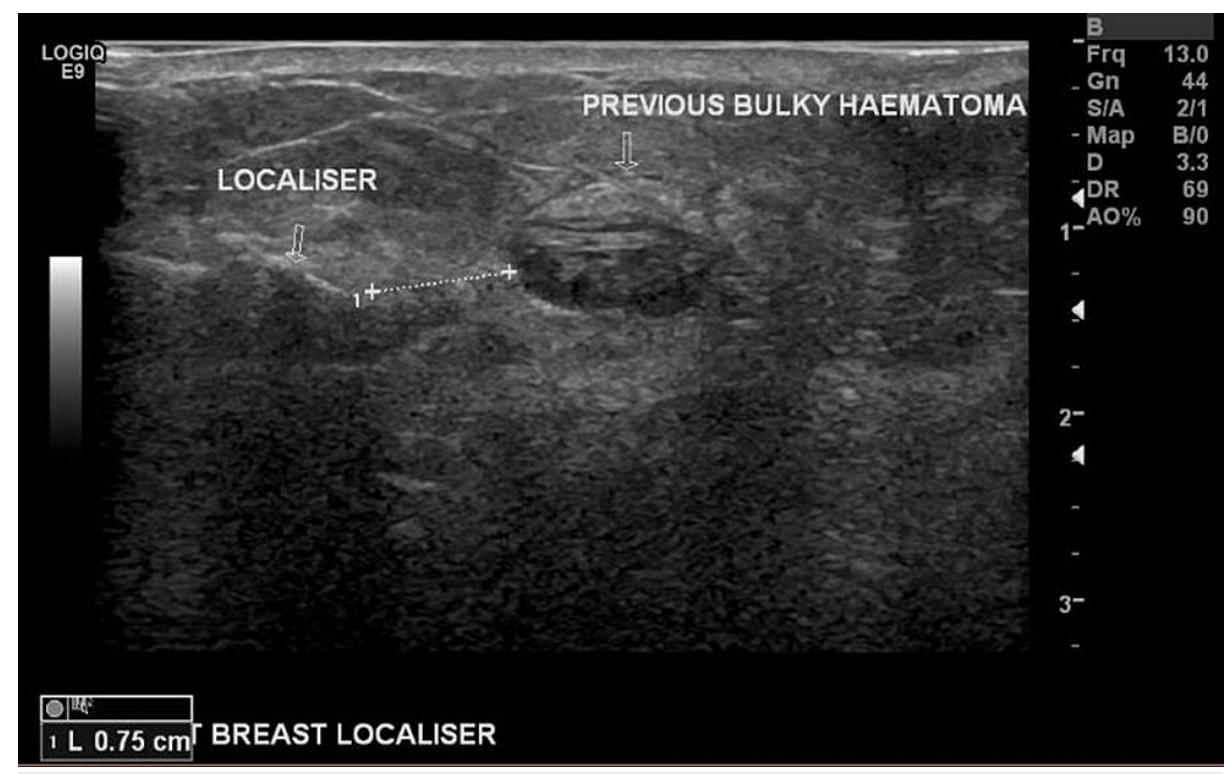

FIGURE 2: Preoperative right breast ultrasound scan showing the cancerous lesion after localization using a radiofrequency identification (RFID) tag

After discussing her care in our multidisciplinary meeting, we preceded with right breast radiofrequency identification (RFID) tag-guided wide local excision (Figure 3), patent blue and radioactive directed sentinel lymph node biopsy (SLNB) and bilateral explantation surrounded by a rim of normal breast tissue (Figure 4). 


\section{Cureus}

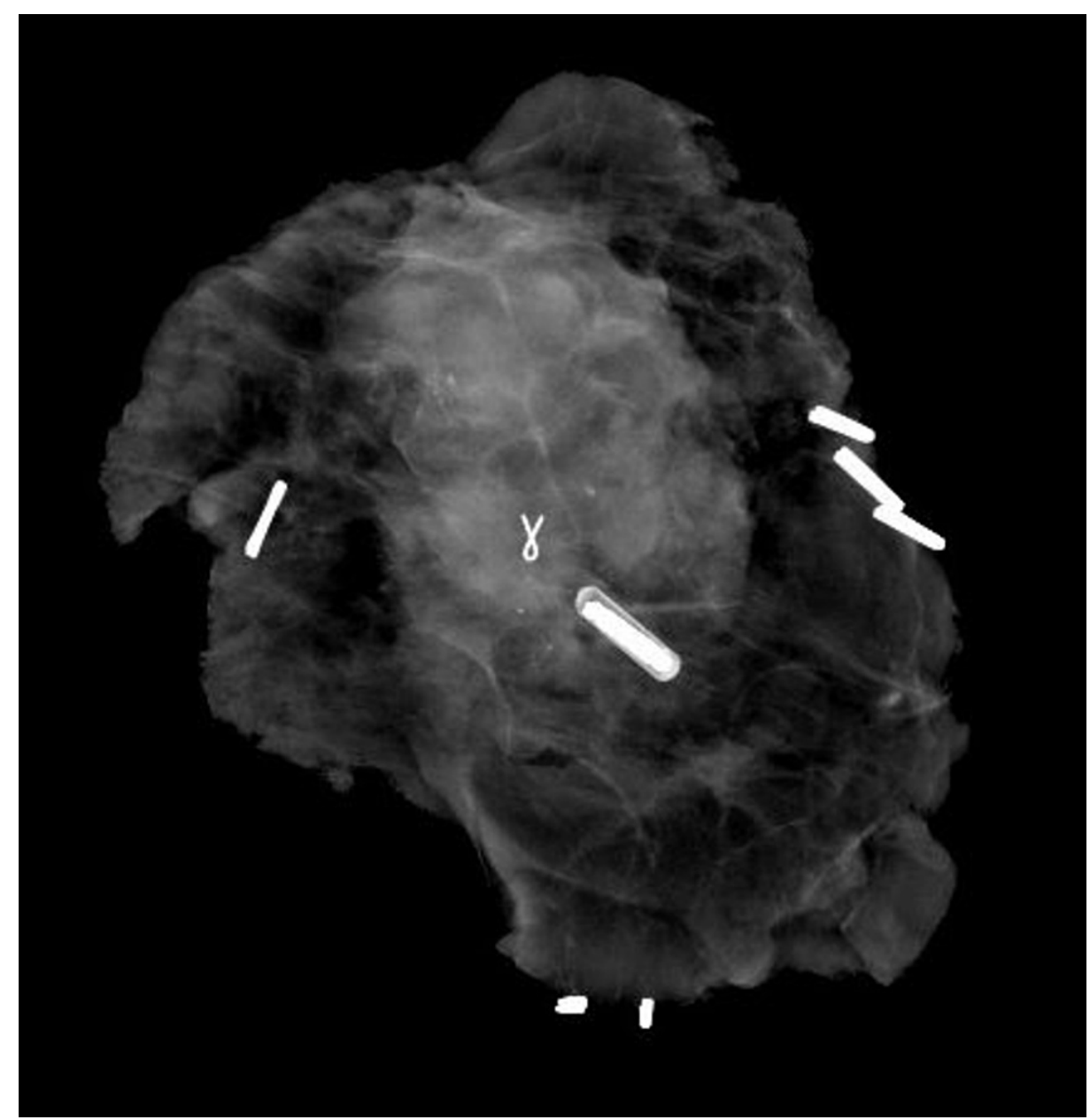

FIGURE 3: Intraoperative X-ray specimen of the right breast wide local excision specimen showing the cancerous index lesion, Titanium clip as well as the radiofrequency identification (RFID) tag 


\section{Cureus}

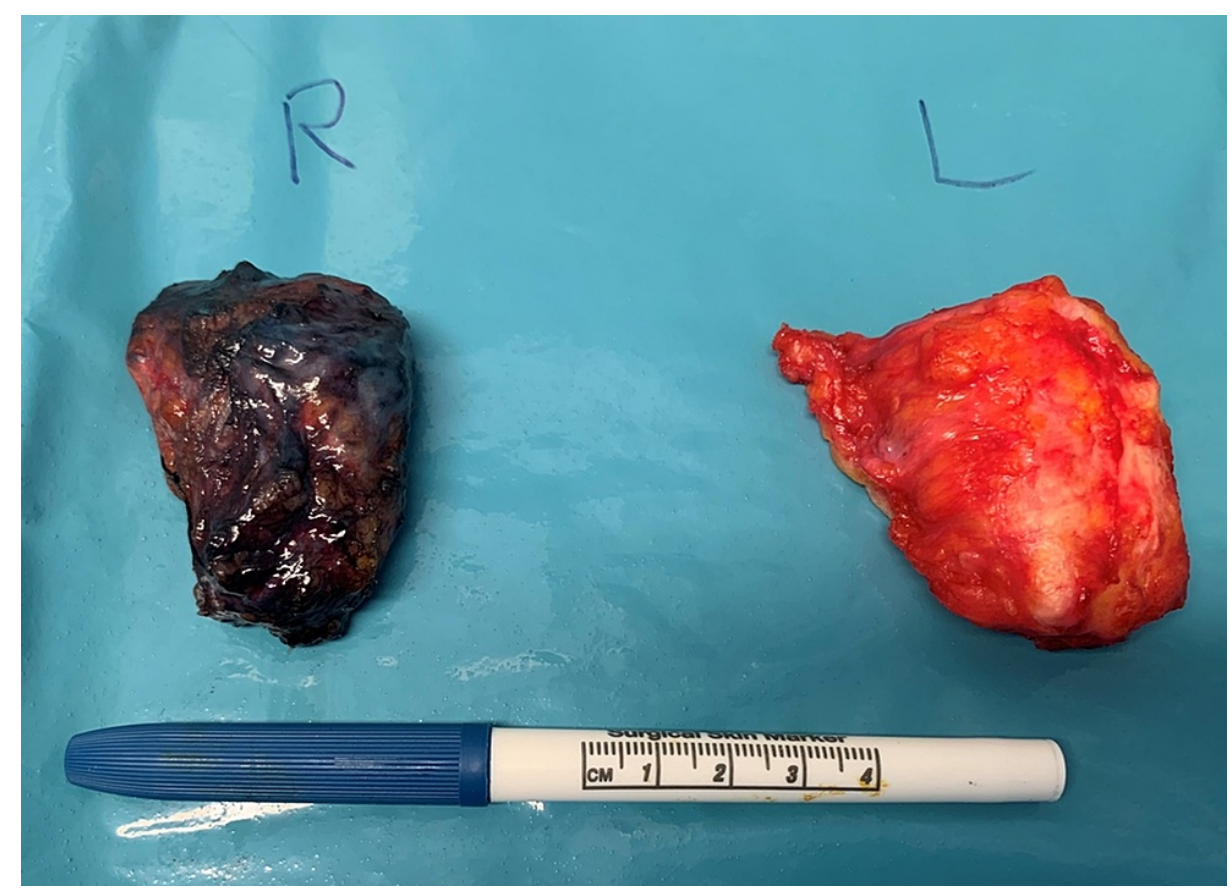

\section{FIGURE 4: Operative specimen showing bilateral excised collapsed implant on the right side; patent blue dye stained the specimen}

The patient had smooth postoperative recovery and was discharged the following day, seen in the clinic the following week with good aesthetic results and no postoperative complications were noted.

Final histology revealed a fully excised, right breast, $17 \mathrm{~mm}$, invasive ductal carcinoma, grade II, with intermediate-grade solid and comedo ductal carcinoma in situ, estrogen receptors (ER) 8, progesterone receptors (PR) 8 and human epidermal growth factor receptor 2 (HER2) negative, and SLNB 0/2. The bilateral collapsed implants showed an extensively calcified capsule lined by a band of dense hyaline fibrous tissue showing patchy dystrophic calcification, with mild chronic inflammation, occasional foreign body giant cells, and fat necrosis noted but no evidence of Breast Implant-Associated Anaplastic Large Cell Lymphoma (BIA-ALCL). Based on the final histology, the patient was offered right breast radiotherapy, followed by endocrine treatment.

\section{Discussion}

Before introducing silicone implants, breast augmentation options included injections of glycerine, silicone oil, autologous fat, ox cartilage and even snake venom, which were associated with a high rate of complications [5]. From 1951 to 1963, a number of different sponges were used for breast augmentation, including polyvinyl alcohol sponge and polyethylene sponge. Still, they were associated with a very high incidence of capsular contracture [6]. In 1963, Cronin and Gerow introduced the first silicone gel breast implant [7]. In 1964, saline implants were introduced by Henry Jenny and Laboratoires Arion in France as a response to refuted silicone worries [8].

In 1969, Ashley introduced anatomical shaped implants covered in polyurethane foam, which was found to have significantly reduced the high rate of capsular contracture [9]. In 1982, Radovan introduced tissue expanders [10]. In 1984, Becker described a dual-chamber expander with a silicone gel outer lumen with an inflatable inner saline lumen, which led to the possibility of having a single-stage breast reconstruction [11].

The incidence and risk factors of implant-related complications vary. Infection is seen in about $2 \%$ of patients; two-thirds develop in the early postoperative period while one-third develops years after surgery. Infection rates are known to be higher after breast reconstruction surgery, especially immediate reconstruction than after breast augmentation [12]. Capsular contracture is another well-recognised complication that can be attributed to low-grade or subclinical infection and biofilm formation [12-13].

The incidence of breast implant failure was found to increase with implant age; about $15 \%$ of implants are expected to fail between the third and tenth years [3]. Yet, in our case, the patient started to feel implantrelated changes in the form of a possible lump, indicating failure about 50 years following implantation. 
implant loss [14]. Therefore, clinicians need to stay vigilant and look out for clinical signs of implant-related complications, especially in elderly patients with breast implants.

The aesthetic outcome of implant-based breast augmentation depends not only on patients' expectations, chest wall shape and symmetry [15], breast shape, consistency and compliance or laxity of the lipocutaneous envelope but also on implant shape, fill and size [16]. Hence, saline-filled implants, which were quite popular in the past, are less popular now with the recent advances in silicone implants.

While some studies have suggested that breast implants can affect the detection of breast cancer at screening settings, Azzi et al. have found that breast implant, either subpectoral or subglandular, does not impact cancer screening [17]. Other studies have also suggested that cosmetic breast augmentation can adversely affect patients' survival, who subsequently develop breast cancer. These findings should be interpreted with caution, as, unfortunately, some of these studies did not adjust for potential confounders [18].

\section{Conclusions}

We believe we have presented one of the very early breast augmentation cases using saline implants. This patient developed breast cancer 50 years after having her implants. Luckily enough, she presented with left implant-related changes, leading to the early diagnosis of her right breast cancer. Our case highlighted the importance of history-taking and triple assessment in ruling out breast implant complications and incidental cancer, especially in geriatric patients, which will aid individualised patient management.

We recommend a meta-analysis of breast cancer patients' management with coexistent breast implants to develop more robust, evidence-based guidelines for managing this group of patients to achieve better outcomes.

\section{Additional Information \\ Disclosures}

Human subjects: Consent was obtained or waived by all participants in this study. Conflicts of interest: In compliance with the ICMJE uniform disclosure form, all authors declare the following: Payment/services info: All authors have declared that no financial support was received from any organization for the submitted work. Financial relationships: All authors have declared that they have no financial relationships at present or within the previous three years with any organizations that might have an interest in the submitted work. Other relationships: All authors have declared that there are no other relationships or activities that could appear to have influenced the submitted work.

\section{References}

1. Duggan MA, Anderson WF, Altekruse S, Penberthy L, Sherman ME: The surveillance, epidemiology, and end results (SEER) program and pathology: Toward strengthening the critical relationship. Am J Surg Pathol. 2016, 40:e94-e102. 10.1097/PAS.0000000000000749

2. McIntosh SA, Horgan K: Breast cancer following augmentation mammoplasty - a review of its impact on prognosis and management. J Plast Reconstr Aesthet Surg. 2007, 60:1127-35. 10.1016/j.bjps.2007.03.017

3. Hölmich LR, Friis S, Fryzek JP, et al.: Incidence of silicone breast implant rupture . Arch Surg. 2003, 138:8016. 10.1001/archsurg.138.7.801

4. Spear SL, Baker JL Jr: Classification of capsular contracture after prosthetic breast reconstruction. Plast Reconstr Surg. 1995, 96:1119-23.

5. The bizarre and painful history of breast implants. All that's interesting . (2020). https://allthatsinteresting.com/weird-history-of-breast-implants.

6. Peters W: The history of biomaterials used for breast augmentation . Biomaterials in Plastic Surgery. W Peters, H Brandon, KL Jerina, C Wolf, VL Young (ed): Woodhead Publishing, Cambridge, United Kingdom; 2012.

7. Cronin TD, Gerow FJ: Augmentation mammaplasty: a new "natural feel” prosthesis . Transact III Internat Congr Plast Surg. 1963,

8. Institute of Medicine (US) Committee on the Safety of Silicone Breast Implants: Safety of Silicone Breast Implants. Bondurant S, Ernster V, Herdman R (ed): National Academies Press (US), Washington (DC); 1999.

9. Ashley FL: A new type of breast prosthesis. Preliminary report . Plast Reconstr Surg. 1970, 45:421-4. 10.1097/00006534-197005000-00001

10. Radovan C: Breast reconstruction after mastectomy using the temporary expander . Plast Reconstr Surg. 1982, 69:195-208. 10.1097/00006534-198202000-00001

11. Becker H: Breast reconstruction using an inflatable breast implant with detachable reservoir . Plast Reconstr Surg. 1984, 73:678-83. 10.1097/00006534-198404000-00031

12. Yoon AP, Qi J, Brown DL, et al.: Outcomes of immediate versus delayed breast reconstruction: results of a multicenter prospective study. Breast. 2018, 37:72-79. 10.1016/j.breast.2017.10.009

13. Constantine RS, Constantine FC, Rohrich RJ: The ever-changing role of biofilms in plastic surgery . Plast Reconstr Surg. 2014, 133:865e-872e. 10.1097/PRS.0000000000000213

14. Walker JN, Poppler LH, Pinkner CL, Hultgren SJ, Myckatyn TM: Establishment and characterization of bacterial infection of breast implants in a murine model. Aesthet Surg J. 2020, 40:516-528. 10.1093/asj/sjz190 


\section{Cureus}

15. Frame JD, Connolly C: Framing the breast. Aesthet Surg J. 2015, 35:NP106-12. 10.1093/asj/sju088

16. Perry D, Frame JD: The history and development of breast implants . Ann R Coll Surg Engl. 2020, 102:478482. 10.1308/rcsann.2020.0003

17. Azzi AJ, Gornitsky J, Viezel-Mathieu A, Lessard L: The impact of implant location on breast cancer characteristics in previously augmented patients: a systematic literature analysis. J Cancer Prev. 2018, 23:93-98. 10.15430/JCP.2018.23.2.93

18. Lavigne E, Holowaty EJ, Pan SY, et al.: Breast cancer detection and survival among women with cosmetic breast implants: systematic review and meta-analysis of observational studies. BMJ. 2013, 346:f2399. 10.1136/bmj.f2399 